\title{
Mortality prediction by 'Life Threat Index' compared to widely used trauma scoring systems
}

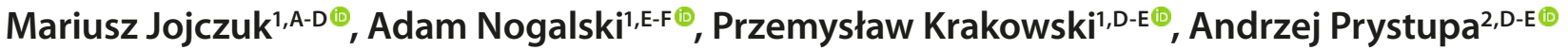 \\ ${ }^{1}$ Chair and Department of Traumatology and Emergency Medicine, Medical University, Lublin, Poland \\ ${ }^{2}$ Department of Internal Medicine, Medical University, Lublin, Poland \\ A - Research concept and design, B - Collection and/or assembly of data, C - Data analysis and interpretation, \\ $D$ - Writing the article, E-Critical revision of the article, F- Final approval of the article
}

Jojczuk M, Nogalski A, Krakowski P, Prystupa A. Mortality prediction by 'Life Threat Index' compared to widely used trauma scoring systems. Ann Agric Environ Med. 2022; 29(2): 258-263. doi: 10.26444/aaem/142182

\begin{abstract}
Introduction and objective. Injuries are an extremely important problem in public life and account for up to one-third of deaths in the entire human population. Available trauma scoring systems provide a good estimation of mortality; however, some factors affect their utility in daily practice. Therefore, a new easily applicable in any given country trauma scoring system has been developed and proposed in this study.

Materials and method. A retrospective study of the medical records of 485 patients were evaluated, together with diagnostic performance with regard to mortality, was calculated for the Revised Trauma Score (RTS), Injury Severity Score (ISS), The New Injury Severity Score (NISS), Trauma and Injury Severity Score (TRISS), International Classification based Injury Severity Score (ICISS) and the newly-developed Life Threat Index (LTI). Sensitivity, specificity, accuracy, PPV and NPV were calculated for each scoring system, and overall diagnostic performance was estimated with the use of ROC curves.

Results. Apart from RTS, all scoring systems showed similar performance regarding mortality prediction. TRISS and LTI showed the highest sensitivity reaching 0.998 and AUC of 0.89 and 0.87 , respectively, which proved its usefulness in predicting mortality.

Conclusions. LTI proved to be one of the most sensitive in comparison with widely-used and recognized trauma scoring systems. Based on LTI methodology, it can be applied in any given country or region, even without a previously developed trauma database.
\end{abstract}

\section{Key words}

trauma, injury, mortality

\section{INTRODUCTION}

Injuries are an extremely important problem in public life, not only because of their medical impact, but also because they often considered as important economical and social factors. Injuries represent $8 \%$ of all deaths in the entire human population. They are, however, also one of the leading causes of death among younger patients, thus generating huge financial losses not only because of absence from work or costs of treatment, but also because of their consequence in the form of a disability or emotional distress, which strongly affects the quality of life [1-6]. Statistics for the global burden of disease (GBD) show that over 900 million people were affected by injury and that 4.8 million patients died in this group worldwide [7] in 2013. The most recent GBD also shows that injuries are responsible for 250 million disabilityadjusted life years (DALY) [8].

During 2007-2015 in just one state in Australia, the costs related to high energy trauma reached over $\$ 14$ billion [9]. Deaths due to injuries make up about $10 \%$ of deaths registered worldwide, but because of the young age of the victims, potential years of life lost (PYLL) estimated due to

Address for correspondence: Przemysław Krakowski, Chair and Department of Traumatology and Emergency Medicine, Medical University, Staszica 11, 20-081 Lublin, Poland

E-mail: przemyslaw.krakowski84@gmail.com

Received: 29.05.2021; accepted: 11.09.2021; first published: 14.10.2021 injuries is definitely the highest when compared to all other causes of deaths and disabilities [10] and, on average, in Western European countries reaches 1,061/100,000 personyears. Therefore, saving lives and preventing disability seems crucial in the economic and social aspects. However, special diagnostic and therapeutic difficulties occur in cases of severe, multiple and multi-organ injuries. This is due to the fact that these type of injuries manifest with numerous pathophysiological and metabolic effects, which are reflected in the general response of the body.

Numerous trauma scoring systems, such as Revised Trauma Score (RTS) [11], Injury Severity Score (ISS) [12], New Injury Severity Score (NISS) [13], Trauma and Injury Severity Score (TRISS) [14], and the International Classification based Injury Severity Score (ICISS) [15], are in used in clinical and academic practice. Each of these scoring systems has its own strengths and weaknesses. ICISS, proposed by Osler et al. [15], a scoring system based on the ICD-9 system, evaluated of over 300,000 patients in North Carolina, USA, and showed the viability of such an evaluation being performed for any given population or country which will be likely to be more objective. In 2008, as a continuation of the concept proposed by Osler et al., Nogalski proposed a Life Threat Index (LTI) (Wskaznik Zagrozenia Zycia - WZŻ) [16], which relies on the ICD-10 classification system and validated on 92,000 patients. This scoring system has proved successful in regions where trauma a database and uniform injury classification 
are lacking, such as in Poland. Although to-date this scoring system has not been widely used, it has nevertheless proved its usefulness and reliability.

The aim of this study was to compare LTI with other injury scoring systems available in literature and in clinical practice, with regard to mortality prediction.

\section{MATERIALS AND METHOD}

A retrospective cohort study was performed on a group of 485 patients admitted as emergency cases and hospitalized in the Department of Trauma Surgery and Emergency Medicine at the Medical University of Lublin, eastern Poland, during a period of one year. The main inclusion criteria were admission to the emergency department in less than 12 hours post injury, adult patients (over 18 years of age), and patients with injuries classified as S00-T19 accordingly to the ICD-10. The mechanism of injury was also classified with the ICD10 in the range of V01-Y98. Patients were divided into 4 age groups: under 30-years-old, 31-50-years-old, 51-70 years old, and over 70-years-old.

The database used for analysis was prepared on medical documentation from the hospital Emergency Department, Department of Trauma Surgery and Emergency Medicine, Department of Anaesthesiology and Intensive Care in Independent Public Clinical Hospital No. 1 in Lublin, Poland.

The database created contained following information: Glasgow Coma Scale for neurological assessment, systolic blood pressure, heart rate, respiratory rate at the time of admission to the Emergency Department. Basic descriptive data, national identification number, age and gender, were collected at the time of admission for further processing. Each patient was then admitted to the hospital, where further diagnostics and treatment was performed. Retrospective analysis of individual medical documentation was performed to determine injury severity using the Abbreviated Injury Scale (AIS) [17], and the given injuries were assigned codes from range $\mathrm{S}-\mathrm{T}$ (according to the ICD-10 classification), beginning with isolated injuries and ending with multiple injuries coded to fourth disease inclusive as well as the mechanism of the injury in the range V-Y (according to the ICD-10 classification). AIS score used for comparison was calculated as the single highest numerical value. The injuries were divided into blunt and penetrating. This data was used to assess severity of the injury in the following scales: Revised Trauma Score (RTS) [11], Injury Severity Score (ISS) [12], New Injury Severity Score (NISS) [13], Trauma and Injury Severity Score (TRISS) [14], International Classification based Injury Severity Score (ICISS) [15], and the newly-developed Life Threat Index (LTI) [16].

LTI such as ICISS is based on the ICD coding system, and the risk factors proposed and calculated by Nogalski assessed for the patients hospitalized in the Lublin Province between 2003-2009. The values of risk factors are provided in appendix 1. For each ICD-10 code corresponding to injuries (S-T), the injury risk factor (IRF) was calculated, for codes describing injury mechanism (V-Y), mechanismrelated risk factor (MRF) was calculated. The age-related risk factor (ARF was calculated for multiple age groups (0-14, 15-24, 25-34, 35-44, 45-54, 55-64, 65-74 and over 74-years-old)
$\mathrm{IRF}=\frac{\text { (number of patients } \text { with given } S-T \text { codes } \text { who survived)/ }}{\text { (number of all patients } \text { with given } S-T)}$

$\mathrm{MRF}=\frac{\text { (number of patients with given } V-Y \text { codes } \text { who survived }) /}{\text { (number of all patients with given } V-Y)}$ $\mathrm{ARF}=\frac{\text { (number of patients with given age group who survived)/ }}{\text { (number of all patients with given age group) }}$

$L T I=M R F \times A R F \times I R F 1 \times I R F 2 \times I R F 3 \ldots I R F n$

The lower the LTI score, the more severe the injury and the higher the mortality rate. Injury severity was divided into three trauma groups: trauma, moderate, and severe, with corresponding LTI, ICISS and TRISS scores: >=0.9; $0.75-0.899$ and $0-0.749$.

Statistical analysis. Statistical analysis was performed bya statistic specialist using IBM SPSS ver. 14.0. For categorial variables, Persons's Chi-square was used. Diagnostic performance of trauma severity score in predicting mortality was evaluated with the Receiver Operating Characteristic Curve (ROC). A predictive model was created for every trauma scoring system, which was then compared between scoring systems. During ROC evaluations, factors such as sensitivity and specificity were taken into consideration, which is easy to use in daily practice[18, 19], as the area under the curve (AUC) is a numerical presentation of diagnostic effectiveness. Positive predictive value (PPV) and negative predictive value (NPP) were calculated, where PPV indicates the probability of death and NPP probability of survival.

\section{RESULTS}

The study group consisted of 485 patients of whom a significant majority were males (58.85\%; $\mathrm{p}<0.0001)$. Patients ages ranged from 18-101 years. Patients aged over 70 constituted over $30 \%$ of the study group. Only $15 \%$ of patients were under 30 of age. Males in this age group sustained injury four times more frequently than females $(\mathrm{p}<0.0001)$. Females had the highest injury rate in the over 70 age group. The demographic characteristics of the study group are presented in Table 1.

Table 1. Demographic characteristic of the study group

\begin{tabular}{|c|c|c|c|c|c|c|c|}
\hline & & & \multicolumn{4}{|c|}{ Age } & \multirow[b]{2}{*}{ Total } \\
\hline & & & $\begin{array}{c}<30- \\
\text { years- } \\
\text { old }\end{array}$ & $\begin{array}{l}31-50- \\
\text { years- } \\
\text { old }\end{array}$ & $\begin{array}{l}51-70- \\
\text { years- } \\
\text { old }\end{array}$ & $\begin{array}{l}\text { 70- } \\
\text { years- } \\
\text { old }\end{array}$ & \\
\hline \multirow{8}{*}{ Gender } & \multirow{4}{*}{ Females } & $\mathrm{N}$ & 13 & 33 & 47 & 106 & 199 \\
\hline & & $\begin{array}{c}\text { Gender } \\
\%\end{array}$ & $6.5 \%$ & $16.6 \%$ & $23.6 \%$ & $53.3 \%$ & $100 \%$ \\
\hline & & Age \% & $17.6 \%$ & $25.0 \%$ & $36.2 \%$ & $71.1 \%$ & $41.0 \%$ \\
\hline & & Total \% & $17.6 \%$ & $25.0 \%$ & $36.2 \%$ & $71.1 \%$ & $41.0 \%$ \\
\hline & \multirow{4}{*}{ Males } & $\mathrm{N}$ & 61 & 99 & 83 & 43 & 286 \\
\hline & & Sex \% & $21.3 \%$ & $34.6 \%$ & $29.0 \%$ & $15.0 \%$ & $100.0 \%$ \\
\hline & & Age \% & $82.4 \%$ & $75.0 \%$ & $63.8 \%$ & $28.9 \%$ & $59.0 \%$ \\
\hline & & Total \% & $12.6 \%$ & $20.4 \%$ & $17.1 \%$ & $8.9 \%$ & $59.0 \%$ \\
\hline \multirow{2}{*}{ Total } & & $\mathrm{N}$ & 74 & 132 & 130 & 149 & 485 \\
\hline & & Total \% & $15.3 \%$ & $27.2 \%$ & $26.8 \%$ & $30.7 \%$ & $100.0 \%$ \\
\hline
\end{tabular}


Over $90 \%$ of all traumas were blunt injuries, which was consistent for all age groups. However, males were more susceptible to penetrating injuries (12.6\%), compared to $3.5 \%$ of females in all age groups. The mortality rate in the study group was $4.52 \%(\mathrm{n}=22)$, and was significantly higher in males $-3.08 \%(n=15)$ vs. females $-1.44 \%(n=7 ; p<0.001)$. The distribution of injuries and the results of mean scores in each scoring system are presented in Table 2.

Table 2. Distribution of injuries depending on gender and age

\begin{tabular}{|c|c|c|c|c|c|c|c|}
\hline & & & \multicolumn{4}{|c|}{ Sex } & \multirow{2}{*}{ Total } \\
\hline & & & \multicolumn{2}{|c|}{ Females } & \multicolumn{2}{|c|}{ Males } & \\
\hline \multirow{8}{*}{$\begin{array}{l}\text { Injury } \\
\text { mechanism }\end{array}$} & \multirow{4}{*}{$\begin{array}{l}\text { Pene- } \\
\text { trating }\end{array}$} & $\mathrm{N}$ & \multicolumn{2}{|c|}{7} & \multicolumn{2}{|c|}{36} & 43 \\
\hline & & $\begin{array}{c}\text { Injury } \\
\text { mechanism } \\
\%\end{array}$ & \multicolumn{2}{|c|}{$16.3 \%$} & \multicolumn{2}{|c|}{$83.7 \%$} & $100.0 \%$ \\
\hline & & Sex \% & \multicolumn{2}{|c|}{$3.5 \%$} & \multicolumn{2}{|c|}{$12.6 \%$} & $8.9 \%$ \\
\hline & & Total \% & \multicolumn{2}{|c|}{$1.4 \%$} & \multicolumn{2}{|c|}{$7.4 \%$} & $8.9 \%$ \\
\hline & & $\mathrm{N}$ & \multicolumn{2}{|c|}{192} & \multicolumn{2}{|c|}{250} & 442 \\
\hline & Blunt & $\begin{array}{c}\text { Injury } \\
\text { mechanism } \\
\%\end{array}$ & \multicolumn{2}{|c|}{$43.4 \%$} & \multicolumn{2}{|c|}{$56.6 \%$} & $100.0 \%$ \\
\hline & & Sex \% & \multicolumn{2}{|c|}{$96.5 \%$} & \multicolumn{2}{|c|}{$87.4 \%$} & $91.1 \%$ \\
\hline & & Total \% & \multicolumn{2}{|c|}{$39.6 \%$} & \multicolumn{2}{|c|}{$51.5 \%$} & $91.1 \%$ \\
\hline \multirow{4}{*}{ Total } & & $\mathrm{N}$ & \multicolumn{2}{|c|}{199} & \multicolumn{2}{|c|}{286} & 485 \\
\hline & & \multirow[t]{3}{*}{ Total \% } & & & \multicolumn{2}{|c|}{$59.0 \%$} & $100.0 \%$ \\
\hline & & & \multicolumn{4}{|c|}{ Age } & \\
\hline & & & $\begin{array}{c}<30- \\
\text { years- } \\
\text { old }\end{array}$ & $\begin{array}{c}31 \\
-50- \\
\text { years- } \\
\text { old }\end{array}$ & $\begin{array}{c}51 \\
-70- \\
\text { years- } \\
\text { old }\end{array}$ & $\begin{array}{l}\text { 70-years- } \\
\text { old }\end{array}$ & Total \\
\hline \multirow{8}{*}{$\begin{array}{l}\text { Injury } \\
\text { mechanism }\end{array}$} & \multirow{4}{*}{$\begin{array}{l}\text { Pene- } \\
\text { trating }\end{array}$} & $\mathrm{N}$ & 11 & 11 & 15 & 6 & 43 \\
\hline & & $\begin{array}{c}\text { Injury } \\
\text { mechanism } \\
\%\end{array}$ & $25.6 \%$ & $25.6 \%$ & $34.9 \%$ & $14.0 \%$ & $100.0 \%$ \\
\hline & & Sex \% & $14.9 \%$ & $8.3 \%$ & $11.5 \%$ & $4.0 \%$ & $8.9 \%$ \\
\hline & & Total \% & $2.3 \%$ & $2.3 \%$ & $3.1 \%$ & $1.2 \%$ & $8.9 \%$ \\
\hline & \multirow{4}{*}{ Blunt } & $\mathrm{N}$ & 63 & 121 & 115 & 143 & 442 \\
\hline & & $\begin{array}{c}\text { Injury } \\
\text { mechanism } \\
\%\end{array}$ & $14.3 \%$ & $27.4 \%$ & $26.0 \%$ & $32.4 \%$ & $100.0 \%$ \\
\hline & & Sex \% & $85.1 \%$ & $91.7 \%$ & $88.5 \%$ & $96.0 \%$ & $91.1 \%$ \\
\hline & & Total \% & $13.0 \%$ & $24.9 \%$ & $23.7 \%$ & $29.5 \%$ & $91.1 \%$ \\
\hline \multirow{2}{*}{ Total } & & $\mathrm{N}$ & 74 & 132 & 130 & 149 & 485 \\
\hline & & Total \% & $15.3 \%$ & $27.2 \%$ & $26.8 \%$ & $30.7 \%$ & $100.0 \%$ \\
\hline
\end{tabular}

Table 3. Mean range of injury severity scoring systems point value

\begin{tabular}{lcc}
\hline & Mean & SD \\
\hline RTS & 11.73 & 1.213 \\
\hline AIS & 2.79 & 0.776 \\
\hline ISS & 9.33 & 6.7 \\
\hline NISS & 10.35 & 8.721 \\
\hline TRISS & 0.9872 & 0.08098 \\
\hline ICISS & 0.94 & 0.092 \\
\hline LTI & 0.9 & 0.099
\end{tabular}

\section{DISCUSSION}

In the injury databases and injury severity scales, AIS, ISS, NISS and TRISS are widely used [20,21]. Their big advantage is data collected regarding this particular group of patients, and provide the possibility of fully assessing the severity of injury. However, there is no uniform system for patient assessment after injury [22]. Almost any trauma centre anywhere in the world can choose an injury scale which is most convenient, popular, or known in a particular country or region, which often does not permit comparison of results of treatment between trauma centres and makes it difficult to create uniform procedures and algorithms.

Scoring systems derived from AIS, such as ISS, NISS or TRISS, are the most popular in literature. However, none of the mentioned systems is uniformly accepted worldwide as the gold standard, and new scoring systems are introduced into literature [23] to provide more accurate and detailed descriptions of patient status. 


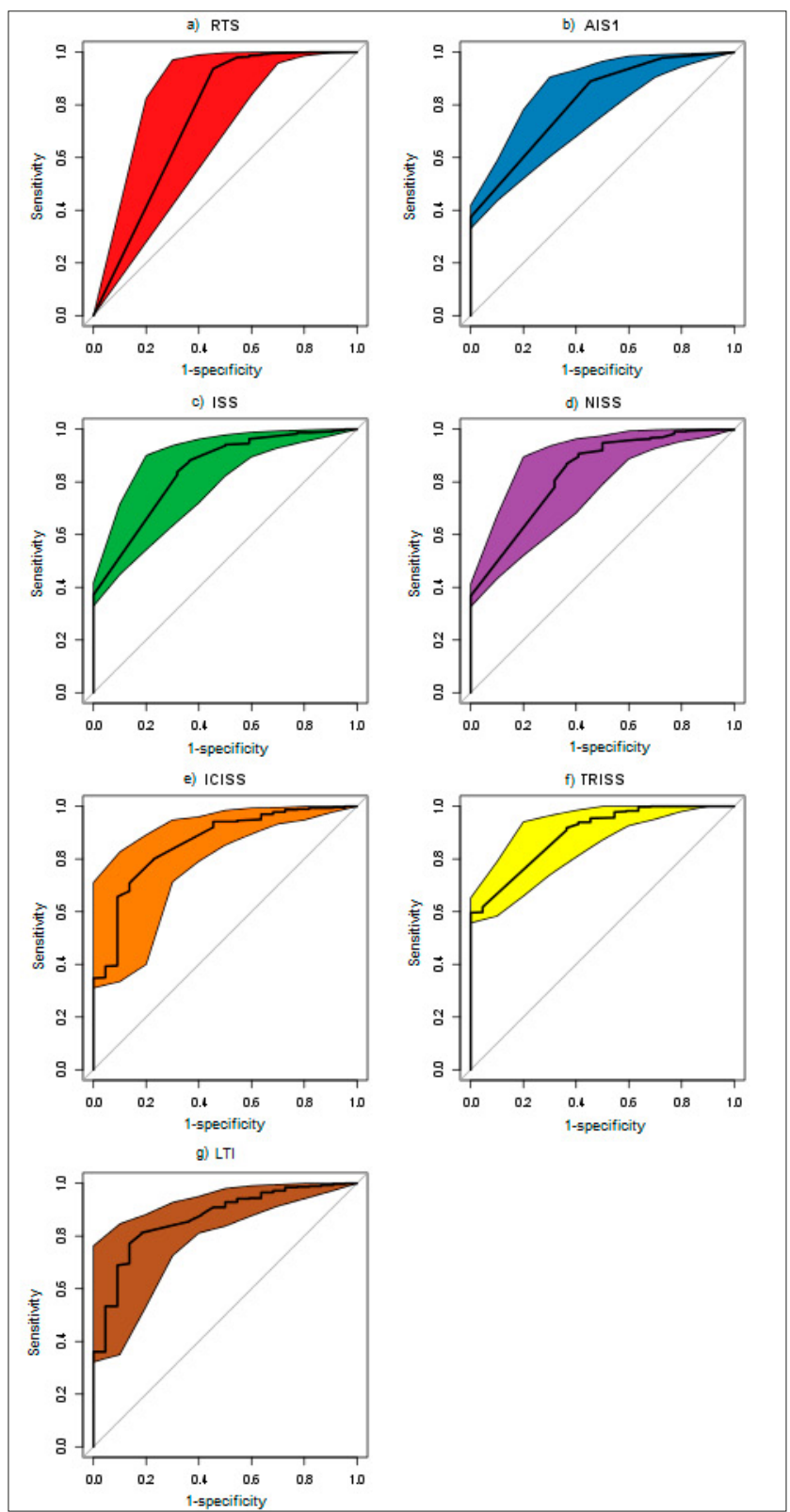

Figure 1. ROC curves for RTS (a), AIS (b), ISS (c), NISS (d), ICISS (e), TRISS (f) and LTI (g) with $95 \% \mathrm{Cl}$

The greatest disadvantage of the above-mentioned scoring systems is believed to be the cost of their use due to several factors. First of all, the copyrights to the AIS classification are owned by the Association for the Advancement of Automotive Medicine. In order to use any of the subsequent editions of AIS classification, copyrights have to be bought. The second issue is the coding problem, where coders can code similar injuries differently, and the coding in this system is a dynamic process and emergency department evaluation is not the end of the coding process. Additional conditions during hospitalization or surgery can also be observed which influence the end-point value of the system; intra-observer agreement is low without special training [24]. These facts render the AIS scale and its derivatives to be unsuitable for use as a diagnostic tool in the pre-hospital period; its complexity requires a certain way of training the coders which significantly increases the costs of its use, especially in middle to low income countries.

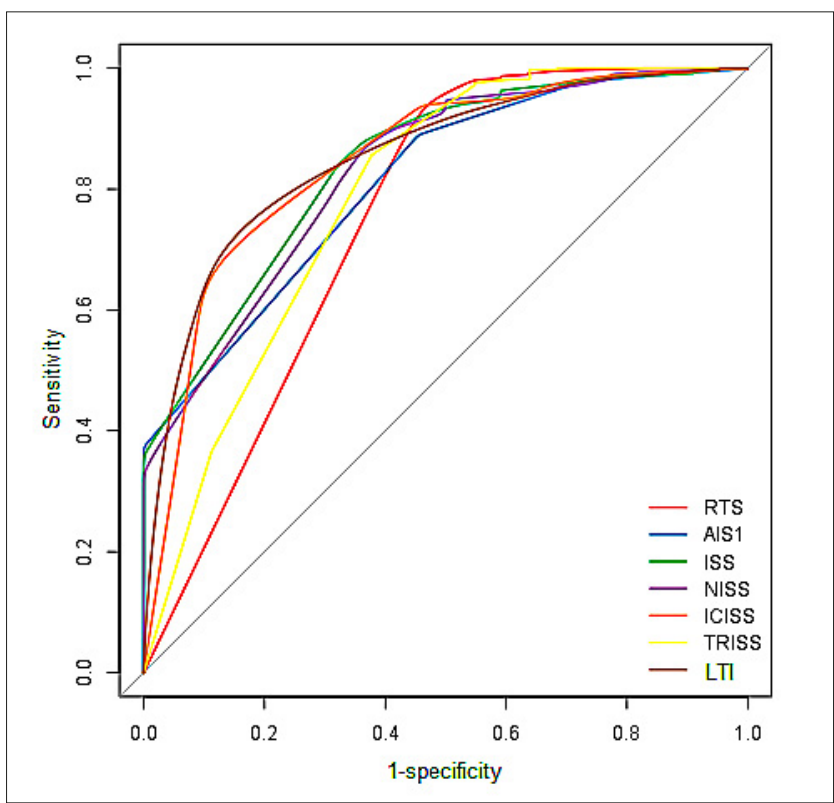

Figure 2. Collective ROC graph presenting results of all evaluated trauma scoring systems

LTI and ICISS have a significant advantage in this respect as they consider all injuries that occurred and multiple injuries are taken under consideration.

When considering point distribution of ISS and NISS in the studied group of patients, it can be noticed that while in scoring according to ISS, the maximum result was 48 points, while the maximum score according to NISS was 66 in the same study group. In addition to the value 48 , which was a maximum for ISS, there were other results, such as 50, 57, 66, appearing in NISS for the same group of patients. This shows that grading according to NISS is more detailed, precise, and describes the results of injury in a better way; however, the most recent meta-analysis shows that there is no significant difference between NISS and ISS in predicting mortality [25]. Another drawback of the system based on AIS is the fact that the age of the patient is not taken into consideration in the calculations. This is the factor which was of critical importance in some cases, such as peritrochanteric fractures where age is widely recognized risk factor [26], but is not included in trauma scoring systems.

TRISS results are dependent on GCS score, which are often changed between EMS and Emergency Departments, which is rather caused by dynamic changes appearing after initial trauma, while GCS showed good inter-observer agreement [27]; therefore, it should be proposed that in TRISS evaluation only one predetermined GCS score should be used, such as GCS evaluation in the Emergency Department. Additionally, RTS which also relies on GCS and other physiological parameters, is susceptible to inappropriate scoring due to changes in a patient's status, or coding differences between coders, and major trauma definitions based on newlyproposed methodology or scales are introduced [28].

The above-mentioned factors speak in favour of trauma scoring systems although they are of an experimental character, e.g. ICISS or LTI, where no acute physiological changes are taken into consideration and cannot influence the end result. In the current study, it was found that LTI is comparable with TRISS, ISS or NISS in predicting mortality $[25,29]$. However, in this study, the mean ISS reached 9.33, 
which shows that the majority of evaluated patients suffered minor trauma, which could have influenced the overall results, and suggests that further larger studies in this aspect should be conducted prior to introducing LTI into wider use around the world.

The current study also showed that, apart from RTS, all scoring systems showed similar diagnostic performance, as also shown by other researchers [30], and ways to improve this scoring system are proposed in literature [31]. The abovementioned factors affecting the widely-used scoring systems outline the need for creating a uniform scoring system which can be introduced worldwide in any given country or region.

The LTI in its original and first form was based on risk factors in the Lublin Province in eastern Poland which are also characteristic for this strictly defined area, and which were used in this study to calculate the value of LTI. Naturally, in order to transfer the LTI methodology, a database of risk factors characteristic for each region or country needs to be developed. This would be relatively easy to achieve without vast additional financing. Moreover, due to fact that LTI is based on the ICD scoring system and shows high sensitivity, it can be applied as a simple triage mechanism for patients with multiple injuries.

The main limitation of ISS is that it is not capable of coding multiple injuries affecting one anatomical location. To avoid this problem, an NISS was proposed where multiple injuries can be assigned to one anatomical location, but no more than three. Some studies show superior diagnostic performance of NISS over ISS in predicting mortality [32]. Nevertheless, in the current study, the same as in a recent meta-analysis by Deng et al [25], the diagnostic performance of ISS and NISS is comparable, regardless of the fact that NISS can include more than one injury in a given anatomical location. This phenomenon does not occur in ICISS and LTI where multiple injuries are included, which results in a higher mortality prognostic value. According to Osler, in the ICISS such factors can be considered. As proven, the more the co-factors considered, the greater the significance of the predictive value in scale improves $[15,33]$. In the current study ICD-10 classification for ICISS calculation was applied which showed a high diagnostic performance with AUC of 0.86 . This corresponds with other researchers showing AUC of $0.852-0.868$ in ICD-10 based ICISS [34-36] with regard to mortality, and 0.815 with regard to ICU admission [35]. Such a high diagnostic performance can be only obtained if survival risk ratios (SRR) are correctly adopted for high, middle or low income countries, as shown by Claeson et al. [37].

It is worth remembering that the ICISS predicting value is only based on SRR calculated for a given ICD code, without taking into consideration other factors that may affect its diagnostic performance. LTI, which incorporates risk factors describing age or injury mechanism, provide a higher diagnostic performance. Also, the amount of risk factors representing specific injuries used to calculate LTI is unlimited, and multiple injuries can be evaluated in a single patient, through which, diagnostic accuracy increases.

The obtained results show that injury severity scales used in the study, such as AIS or ISS, based only on anatomical deviations from the norm in the injury examination, as well as physiological response of the organism to injury such as RTS, proved to be inferior in predicting mortality or patient survival, than much more complicated scales such as TRISS, LTI or ICISS.
Taking the results of this study into consideration, it is proposed that in the setting of an Emergency Department, the teams of emergency medics and areas of the hospital Emergency Department, the Revised Trauma Score, Glasgow Coma Scale, and assessment of basic physiological parameters, should be used, as well as additional tests to provide a basis for making the decision about admitting patient to the hospital or not. When the patient arrives in the hospital and is fully diagnosed, it is proposed that prognostic scales such as LTI or TRISS. RTS and GCS should be used by the teams of emergency medics and the hospital Emergency Department, due to little amount of time needed for collection of all necessary data and ease of data collection for evaluation. More detailed and time-consuming scoring systems, such as LTI or TRISS, seem most applicable in the next step of treatment due to their good diagnostic and predictive properties.

\section{CONCLUSIONS}

LTI proved to be an effective tool compared to other widelyused and recognized trauma scoring systems. All evaluated injury scales, apart from RTS, showed high and similar accuracy in predicting mortality. The methodology of LTI enabling inclusion of multiple factors such as the injury mechanism or patients age, as well as multiple ICD based codes, provide adequate diagnostic accuracy and the ability to implement this system in any given region or country.

\section{REFERENCES}

1. Kaske S, Lefering R, Trentzsch H, Driessen A, Bouillon B, Maegele M, et al. Quality of life two years after severe trauma: A single centre evaluation. Injury. 2014; 45: S100-5. Available from: https://linkinghub. elsevier.com/retrieve/pii/S002013831400388X

2. Herrera-Escobar JP, Rivero R, Apoj M, Geada A, Villanyi M, Blake $\mathrm{D}$, et al. Long-term social dysfunction after trauma: What is the prevalence, risk factors, and associated outcomes? Surgery. 2019; 166(3): 392-7. Available from: https://linkinghub.elsevier.com/retrieve/pii/ S0039606019301849

3. Mutschler W, Mutschler M, Graw M, Lefering R. Langzeitüberleben nach schwerem Trauma. Unfallchirurg. 2016; 119(7): 546-53. Available from: http://link.springer.com/10.1007/s00113-016-0185-1

4. Herrera-Escobar JP, Seshadri AJ, Rivero R, Toppo A, Al Rafai SS, Scott JW, et al. Lower education and income predict worse long-term outcomes after injury. J Trauma Acute Care Surg. 2019; 87(1): 104-10.

5. Herrera-Escobar JP, Al Rafai SS, Seshadri AJ, Weed C, Apoj M, Harlow A, et al. A multicenter study of post-traumatic stress disorder after injury: Mechanism matters more than injury severity. Surgery. 2018; 164(6): 1246-50.

6. World Health Organization. Injuries and violence. [cited 2021 Sep 2]. Available from: https://www.who.int/news-room/fact-sheets/detail/ injuries-and-violence

7. Haagsma JA, Graetz N, Bolliger I, Naghavi M, Higashi H, Mullany EC, et al. The global burden of injury: incidence, mortality, disability-adjusted life years and time trends from the Global Burden of Disease study 2013. Inj Prev. 2016; 22(1): 3-18. Available from: http://injuryprevention.bmj. com/lookup/doi/10.1136/injuryprev-2015-041616

8. Kyu HH, Abate D, Abate KH, Abay SM, Abbafati C, Abbasi N, et al. Global, regional, and national disability-adjusted life-years (DALYs) for 359 diseases and injuries and healthy life expectancy (HALE) for 195 countries and territories, 1990-2017: a systematic analysis for the Global Burden of Disease Study 2017. The Lancet. 2018; 392(10159): 1859-922. Available from: https://linkinghub.elsevier.com/retrieve/ pii/S0140673618323353

9. Beck B, Cameron PA, Fitzgerald MC, Judson RT, Teague W, Lyons RA, et al. Road safety: serious injuries remain a major unsolved problem. Med J Aust. 2017; 207(6): 244-9. 
10. World Health Organization, Department for the Management of Noncommunicable Diseases D Violence and Injury Prevention. Injuries and violence: the facts 2014. 2014 [cited 2020 Jun 1]. Available from: http://apps.who.int/iris/bitstream/10665/149798/1/9789241508018_ eng.pdf?ua=1

11. Champion HR, Sacco WJ, Copes WS, Gann DS, Gennarelli TA, Flanagan ME. A Revision of the Trauma Score: J Trauma Inj Infect Crit Care. 1989; 29(5): 623-9. Available from: http://journals.lww. com/00005373-198905000-00017

12. Greenspan L, McLELLAN BA, Greig H. Abbreviated Injury Scale and Injury Severity Score: A Scoring Chart. J Trauma Inj Infect Crit Care. 1985; 25(1): 60-4. Available from: http://journals.lww.com/00005373198501000-00010

13. Osler T, Baker SP, Long W. A Modification of the Injury Severity Score That Both Improves Accuracy and Simplifies Scoring: J Trauma Inj Infect Crit Care. 1997; 43(6): 922-6. Available from: http://journals. lww.com/00005373-199712000-00009

14. Boyd CR, Tolson MA, Copes WS. Evaluating trauma care: the TRISS method. Trauma Score and the Injury Severity Score. J Trauma. 1987; 27(4): 370-8.

15. Osler T, Rutledge R, Deis J, Bedrick E. ICISS: An International Classification of Disease-9 Based Injury Severity Score. J Trauma Inj Infect Crit Care. 1996; 41(3): 380-8. Available from: http://journals. lww.com/00005373-199609000-00002

16. Nogalski A, Instytut Zastosowań Techniki (Lublin). Wykorzystanie klasyfikacji ICD-10 do określenia ciężkości obrażeń na podstawie współczynników ryzyka dla populacji poszkodowanych w wyniku urazów w regionie lubelskim: praca na stopień doktora habilitowanego nauk medycznych. Lublin: IZT; 2008.

17. Garthe E, States JD, Mango NK. Abbreviated Injury Scale Unification: The Case for a Unified Injury System for Global Use. J Trauma Inj Infect Crit Care. 1999; 47(2): 309-23. Available from: http://journals. lww.com/00005373-199908000-00016

18. Krakowski P, Karpiński R, Jojczuk M, Nogalska A, Jonak J. Knee MRI Underestimates the Grade of Cartilage Lesions. Appl Sci. 2021; 11(4): 1552.

19. Krakowski P, Nogalski A, Jurkiewicz A, Karpiński R, Maciejewski R, Jonak J. Comparison of Diagnostic Accuracy of Physical Examination and MRI in the Most Common Knee Injuries. Appl Sci. 2019; 9(19): 4102.

20. Lecky F, Woodford M, Edwards A, Bouamra O, Coats T. Trauma scoring systems and databases. Br J Anaesth. 2014; 113(2): 286-94.

21. Loftis KL, Price J, Gillich PJ. Evolution of the Abbreviated Injury Scale: 1990-2015. Traffic Inj Prev. 2018; 19(sup2): S109-13.

22. David JS, Bouzat P, Raux M. Evolution and organisation of trauma systems. Anaesth Crit Care Pain Med. 2019; 38(2): 161-7.

23. Cassignol A, Markarian T, Cotte J, Marmin J, Nguyen C, Cardinale $\mathrm{M}$, et al. Evaluation and Comparison of Different Prehospital Triage Scores of Trauma Patients on In-Hospital Mortality. Prehosp Emerg Care. 2019; 23(4): 543-50.

24. Joosse P, de Jongh MAC, van Delft-Schreurs CCHM (Katinka), Verhofstad MHJ, Goslings JC. Improving Performance and Agreement in Injury Coding Using the Abbreviated Injury Scale: A Training Course Helps. Health Inf Manag J. 2014; 43(2): 17-22.

25. Deng Q, Tang B, Xue C, Liu Y, Liu X, Lv Y, et al. Comparison of the Ability to Predict Mortality between the Injury Severity Score and the New Injury Severity Score: A Meta-Analysis. Int J Environ Res Public Health. 2016; 13(8): 825. Available from: http://www.mdpi. com/1660-4601/13/8/825

26. Mattisson L, Bojan A, Enocson A. Epidemiology, treatment and mortality of trochanteric and subtrochanteric hip fractures: data from the Swedish fracture register. BMC Musculoskelet Disord. 2018; 19(1):
369. Available from: https://bmcmusculoskeletdisord.biomedcentral. com/articles/10.1186/s12891-018-2276-3

27. Reith FCM, Van den Brande R, Synnot A, Gruen R, Maas AIR. The reliability of the Glasgow Coma Scale: a systematic review. Intensive Care Med. 2016; 42(1): 3-15. Available from: http://link.springer. com/10.1007/s00134-015-4124-3

28. Roden-Foreman JW, Rapier NR, Foreman ML, Zagel AL, Sexton KW, Beck WC, et al. Rethinking the definition of major trauma: The need for trauma intervention outperforms Injury Severity Score and Revised Trauma Score in 38 adult and pediatric trauma centers. J Trauma Acute Care Surg. 2019; 87(3): 658-65. Available from: http://journals.lww. com/01586154-201909000-00025

29. Yadollahi M, Kashkooe A, Rezaiee R, Jamali K, Niakan MH. A Comparative Study of Injury Severity Scales as Predictors of Mortality in Trauma Patients: Which Scale Is the Best? Bull Emerg Trauma. 2020; 8(1): 27-33. Available from: http://beat.sums.ac.ir/article_46349.html

30. Galvagno SM, Massey M, Bouzat P, Vesselinov R, Levy MJ, Millin MG, et al. Correlation Between the Revised Trauma Score and Injury Severity Score: Implications for Prehospital Trauma Triage. Prehosp Emerg Care. 2019; 23(2): 263-70. Available from: https://www.tandfonline. com/doi/full/10.1080/10903127.2018.1489019

31. Kim SC, Kim DH, Kim TY, Kang C, Lee SH, Jeong JH, et al. The Revised Trauma Score plus serum albumin level improves the prediction of mortality in trauma patients. Am J Emerg Med. 2017; 35(12): 18826. Available from: https://linkinghub.elsevier.com/retrieve/pii/ S0735675717304710

32. Domingues C de A, Sousa RMC de, Nogueira L de S, Poggetti RS, Fontes B, Muñoz D. The role of the New Trauma and Injury Severity Score (NTRISS) for survival prediction. Rev Esc Enferm USP. 2011; 45(6): 1353-8. Available from: http://www.scielo.br/scielo.php?script=sci_ arttext\&pid=S0080 $-62342011000600011 \& \operatorname{lng}=$ en\&tlng=en

33. Hannan EL, Farrell LS, Gorthy S-FH, Bessey PQ, Cayten CG, Cooper A, et al. Predictors of Mortality in Adult Patients with Blunt Injuries in New York State: A Comparison of the Trauma and Injury Severity Score (TRISS) and the International Classification of Disease, Ninth Revision-based Injury Severity Score (ICISS). J Trauma Inj Infect Crit Care. 1999; 47(1): 8-14. Available from: http://journals.lww. com/00005373-199907000-00003

34. Gedeborg R, Warner M, Chen L-H, Gulliver P, Cryer C, Robitaille $\mathrm{Y}$, et al. Internationally comparable diagnosis-specific survival probabilities for calculation of the ICD-10-based Injury Severity Score: J Trauma Acute Care Surg. 2014; 76(2): 358-65. Available from: http:// journals.lww.com/01586154-201402000-00015

35. Gagné M, Moore L, Sirois M-J, Simard M, Beaudoin C, Kuimi BLB. Performance of International Classification of Diseases-based injury severity measures used to predict in-hospital mortality and intensive care admission among traumatic brain-injured patients: J Trauma Acute Care Surg. 2017; 82(2): 374-82. Available from: http://content. wkhealth.com/linkback/openurl?sid=WKPTLP:landingpage\& an $=01586154-201702000-00020$

36. Gagné M, Moore L, Beaudoin C, Batomen Kuimi BL, Sirois M-J. Performance of International Classification of Diseases-based injury severity measures used to predict in-hospital mortality: A systematic review and meta-analysis. J Trauma Acute Care Surg. 2016; 80(3): 419-26. Available from: http://content.wkhealth.com/linkback/ope nurl?sid=WKPTLP:landingpage\&an $=01586154-201603000-00009$

37. Claeson A, Sterner M, Attergrim J, Khajanchi M, Kumar V, Saha $\mathrm{M}$ lal, et al. Assessment of the predictive value of the International Classification of Diseases Injury Severity Score for trauma mortality in urban India. J Surg Res. 2018; 229: 357-64. Available from: https:// linkinghub.elsevier.com/retrieve/pii/S0022480418302397 